\title{
Optimization of culture conditions for antibacterial substance production from newly isolated Brevibacillus laterosporus EA62
}

\author{
Elif Demirkan๑, Aynur Aybey॰, Alev Usta Ak๑ \\ Department of Biology, Bursa Uludă̆ University, Faculty of Arts and Sciences, Bursa, Turkey
}

\section{ABSTRACT}

Objectives: In the present study, it was reported the effects of some nutritional (amino acid, carbon, nitrogen and metal sources) and physical factors ( $\mathrm{pH}$ and temperature) on antibacterial substance activity of Brevibacillus laterosporus EA62.

Methods: The agar well diffusion assay was performed to evaluate the antibacterial activity of the substance. The antibacterial activity of the new substance was examined against four pathogenic bacteria under different nutritional and physical conditions.

Results: The best antibacterial activity was obtained in modified medium consists of the 5\% glucose, $0.1 \%$ tryptone, $0.05 \% \mathrm{MgSO} 4+\mathrm{CaCO} 3$ and $0.5 \%$ glutamic acid. For physical parameters, maximal activity was observed after $72 \mathrm{~h}$ when incubated at $37^{\circ} \mathrm{C}$, pH 7.0.

Conclusions: This study indicates that Brevibacillus laterosporus EA62 could be an important source of antibacterial substances under this medium optimization.

Keywords: This study indicates that Brevibacillus laterosporus EA62 could be an important source of antibacterial substances under this medium optimization.

A ntibiotics are chemicals which kill or inhibit the growth of bacteria or fungi, and can be used to treat infections by these organisms. Antibiotics are the one of the most important commercially exploited secondary metabolites produced by bacteria, fungi and Streptomyces and employed in a wide range. In recent years, soil bacteria have been investigated in terms of antibiotic production potential. The soil is a natural source for microorganisms and their antimicrobial products [1]. Soil bacteria and fungi have played a significant and an important role in antimicrobial product discovery. The selection of natural antimicrobial products from soil microorganisms is considered as analternative method for the disease control and plant protection. Considerable research is being done in order to find new antimicrobial producing bacteria isolated from soil and their active substances $[2,3]$. Several classes of antimicrobial substances that inhibit the growth of fungi and bacteria in vitro assays have been identified in the last decades [4].

Brevibacillus is omnipresent in agricultural soils, and it can secrete structurally diverse secondary metabolites with broad antibiotic spectra. Some of these metabolites, such as chitinaseand gramicidin $\mathrm{S}$, have been extensively studied, and numerous Brevibacillus species, which have the potential as antimicrobial agents, have become research hotspots in the recent years [5]. Brevibacillus laterosporus can pro- 
duce different virulence factors: parasporal crystalline [6], extracellular protease [7] and lipopeptide antibiotics [8]. Additionally, B. laterosporus also secretes short sequencepeptides with broad antibiotic spectra, such as loloatin A [9]; however, these metabolites have not been extensively studied.

The number of multi-drug resistant bacterial strains has increased, partly due to the misuse of antibiotics, resulting in serious health challenges in hospital settings. Thus, the discovery of new potential antibacterial substance producing microorganisms has become an important goal. Many species, such as Streptomyces, Bacillus and Penicillium have been studied continuously for their ability to produce antibiotics [10]. Environmental factors such as $\mathrm{pH}$, temperature and medium composition can influence the production of antagonistic substances from bacteria. Several reports have been discussed regarding antibacterial components, its optimizing by altering several physical factors and medium composition [11-13]. In the present study, it has been optimized nutritional and physical parameters to produce for antibacterial substance of B. laterosporus EA62.

\section{METHODS}

\section{Bacterial Strains and Growth Conditions}

B. laterosporus EA62 which was isolated and identified by $16 \mathrm{~S}$ rRNA gene analysis in the previous study, was used in the current study [14]. Basal growth medium was consisted of $15 \mathrm{~g} / \mathrm{L}$ glucose, $1 \mathrm{~g} / \mathrm{L}$ yeast extract, $0.5 \mathrm{~g} / \mathrm{L} \mathrm{MgSO} 4,3 \mathrm{~g} / \mathrm{L} \mathrm{CaCO} 3$ and $0.5 \mathrm{~g} / \mathrm{L}$ (NH4)2HPO4 at $\mathrm{pH}$ 7.0. The overnight cultures adjusted $108 \mathrm{CFU} / \mathrm{ml}$ were inoculated at $10 \%$ in $150 \mathrm{~mL}$ of basal media and incubated at $37{ }^{\circ} \mathrm{C}$ at $150 \mathrm{rpm}$ for $72 \mathrm{~h}$ [14]. After incubation, samples were filtered through a $0.22 \mu \mathrm{m}$ filter, and the filtrate as antibacterial substance was subsequently used to determine the effects of nutritional and physical parameters on antibacterial substance activity against some pathogenic Gram-negative Yersinia enterocolitica (ATCC 9610) and Salmonella typhimurium (ATCC 14028) the Gram-positive bacteria, Staphylococcus aureus (ATCC 25923) and Enterococcus faecalis (ATCC 29212) by using agar well diffusion assay [15].

Effects of Different Nutritional and Physical Pa- rameters on Production of Antibacterial Substance

Carbon sources including sucrose, maltose, potato starch and wheat bran $(1.5 \% \mathrm{w} / \mathrm{v})$, nitrogen sources including organic (corn step liquor, tryptone and skim milk at $0.1 \% \mathrm{w} / \mathrm{v})$ and inorganic sources ((NH4)2NO3 and $(\mathrm{NH} 4) 2 \mathrm{SO} 3$ at $0.05 \% \mathrm{w} / \mathrm{v})$ were evaluated for their effect of antibacterial substance activityin basal medium. In addition, amino acids including alanine, phenylalanine, valine, tyrosine, lysine, histidine, cystine, arginine, glutamic acid $(0.5 \% \mathrm{w} / \mathrm{v})$ were tested to obtain the best amino acid. The culture medium was supplemented with metal ions such as $\mathrm{CaCl} 2, \mathrm{FeSO} 4$, LiSO4, NaCl, $\mathrm{CaCO} 3, \mathrm{MgSO} 4$, and $\mathrm{MnSO} 4$ (0.05\% w/v)in basal medium.

Antibacterial substance (grown in basal medium for $72 \mathrm{~h}$ ) was exposed to various temperatures. Sterile filtered antibacterial substances were incubated for 1530 min at $30,40,45,50$ and $55^{\circ} \mathrm{C}$ at the optimal $\mathrm{pH}$ of 7.0 and then immediately cooled in ice water. A control was maintained by incubating antibacterial substances at $37 \mathrm{oC}$. For optimizing $\mathrm{pH}$, different $\mathrm{pH}$ was estimated by adjusting $\mathrm{pH}$ of antibacterial substances to the 4.0 to 9.0. After incubation for $1 \mathrm{~h}$ and before plating for antibacterial activity, $\mathrm{pH}$ treated samples were neutralized $\mathrm{pH}$ 6.5-7 to determine the antibacterial substance activity.

\section{Statistical Analysis}

For statistical analysis, the standard deviation for each experimental result and student's t-test were calculated using Microsoft Excel. All of the assays were carried out in triplicate. The bars correspond to standard deviation [16].

\section{RESULTS}

In this study, it was carried out to determine the antibacterial substance activity of $B$. laterosporus EA62 by assessing the effect of nutritional and physical conditions. The isolate was inoculated in basal medium and incubated at $37 \mathrm{oC}$ for $72 \mathrm{~h}$; the filtered supernatant as antibacterial substance wasused to determine the antibacterialactivity against $Y$. enterocolitica, S. typhimurium, S. aureus and E. faecalis under various nutritional and physical conditions.

The basal medium was optimized with different carbon and nitrogen sources, metal ions and amino acids. 


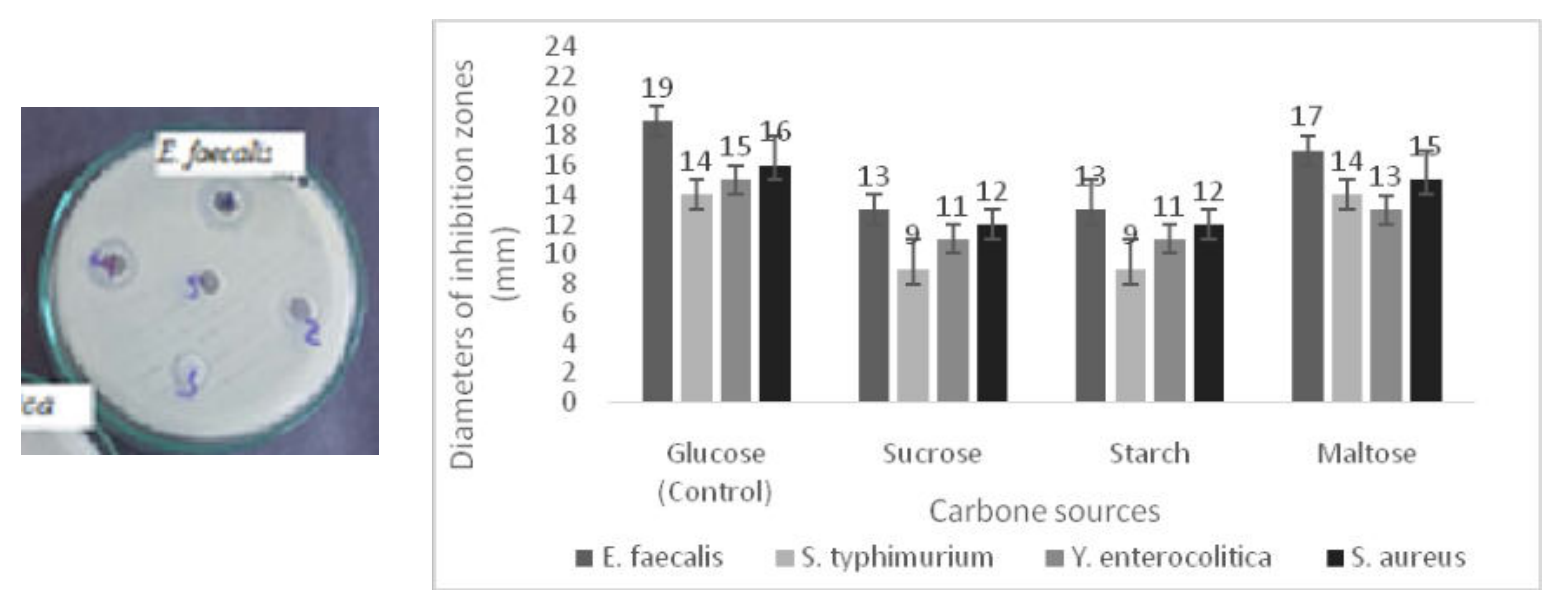

Fig. 1. Effect of different carbon sources on the production of antibacterial substance against pathogens. 1-Glucose, 2-Sucrose, 3-Starch, 4-Maltose, 5-Wheat bran on petri dish.

Among the different carbon and nitrogen sources studied, addition of glucose (Fig.1) and tryptone (Fig. 2) to the basal medium showed highest antibacterial activity against $E$. faecalis. Our data showed that glucose $(19 \mathrm{~mm})$ followed maltose $(17 \mathrm{~mm})$ against $E$. faecalis and glucose $(16 \mathrm{~mm})$ followed maltose $(15 \mathrm{~mm})$ against $S$. aureus enhanced the antimicrobial activity. No antibacterial activity was observed using wheat bran (Fig. 1). The production of antibacterial substance was repressed by wheat bran.

Among nitrogen sources, higher antibacterial activity was achieved when tryptone $(20 \mathrm{~mm})$ and yeast extract $(19 \mathrm{~mm})$ against $E$. faecalis used as a nitrogen source followed tryptone $(17 \mathrm{~mm})$ and yeast extract (17 mm) against $S$. typhimurium. In this study, yeast extract and tryptone alone appeared more efficient at the activity of the antibacterial substance and antibacterial activity was not observed in the presence of skim milk as organic nitrogen source.

Some amino acids were tested in the basal medium to determined inhibitory effects of the antibacterial substance in this study. Glutamic acid has the most effective amino acid on antibacterial substance activity against all bacteria tested, while valine and arginine has the least, phenylalanine and cysteine resulted in no antibacterial substance activity (Fig. 3). Maximum zone of inhibition in basal medium containing glutamic acid was observed against $S$. aureus (19 $\mathrm{mm}$ ) followed bylisine $(17 \mathrm{~mm})$ and alanine $(17 \mathrm{~mm})$ against $E$. faecalis.

In this study, a small effect was only observed for $\mathrm{MgSO} 4$ and $\mathrm{MgSO} 4+\mathrm{CaCO} 3$ combination among the metal ions, no antibacterial activity was obtained in the presence of the others (Fig. 4). Results showed that a synergistic effect of $\mathrm{MgSO} 4$ and $\mathrm{CaCO} 3$ on the antibacterial substance activity occurred and antibacter-
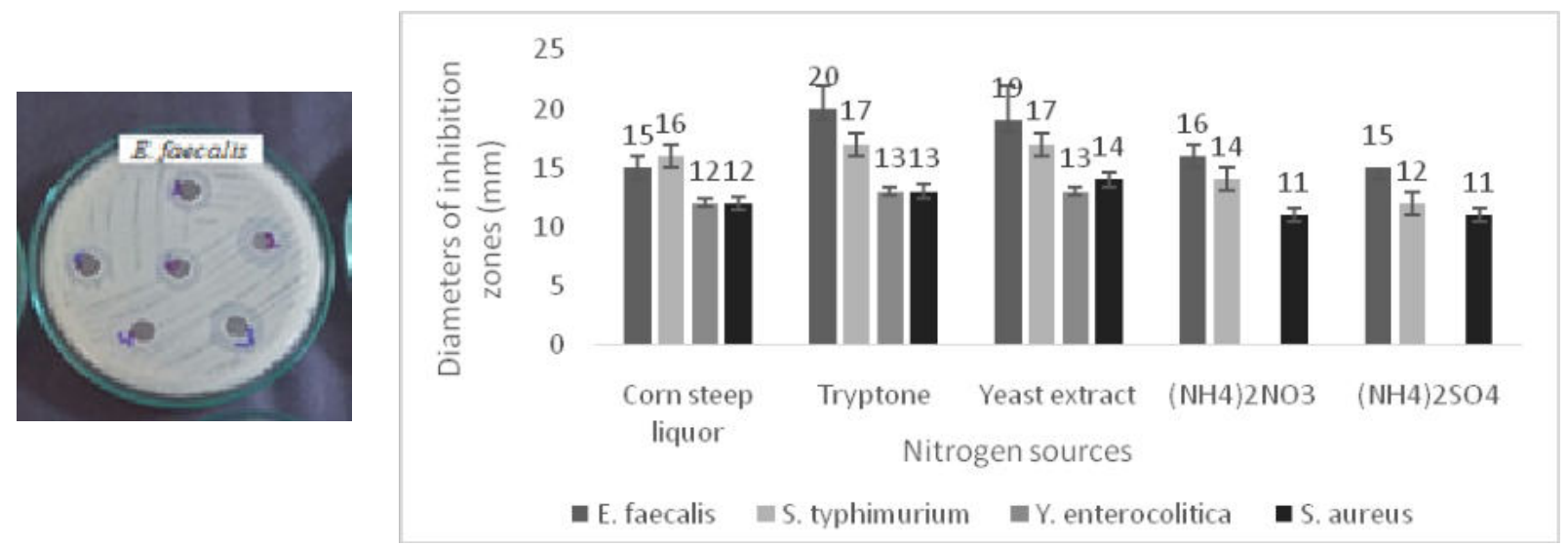

Fig. 2. Effect of different nitrogen sources on the production of antibacterial substance against pathogens. 1-Corn steep Liquor, 2-Tryptone, 3-Yeast extract, 4-Skim milk, 5-(NH4)2NO3, 6-(NH4)2SO3on petri dish. 


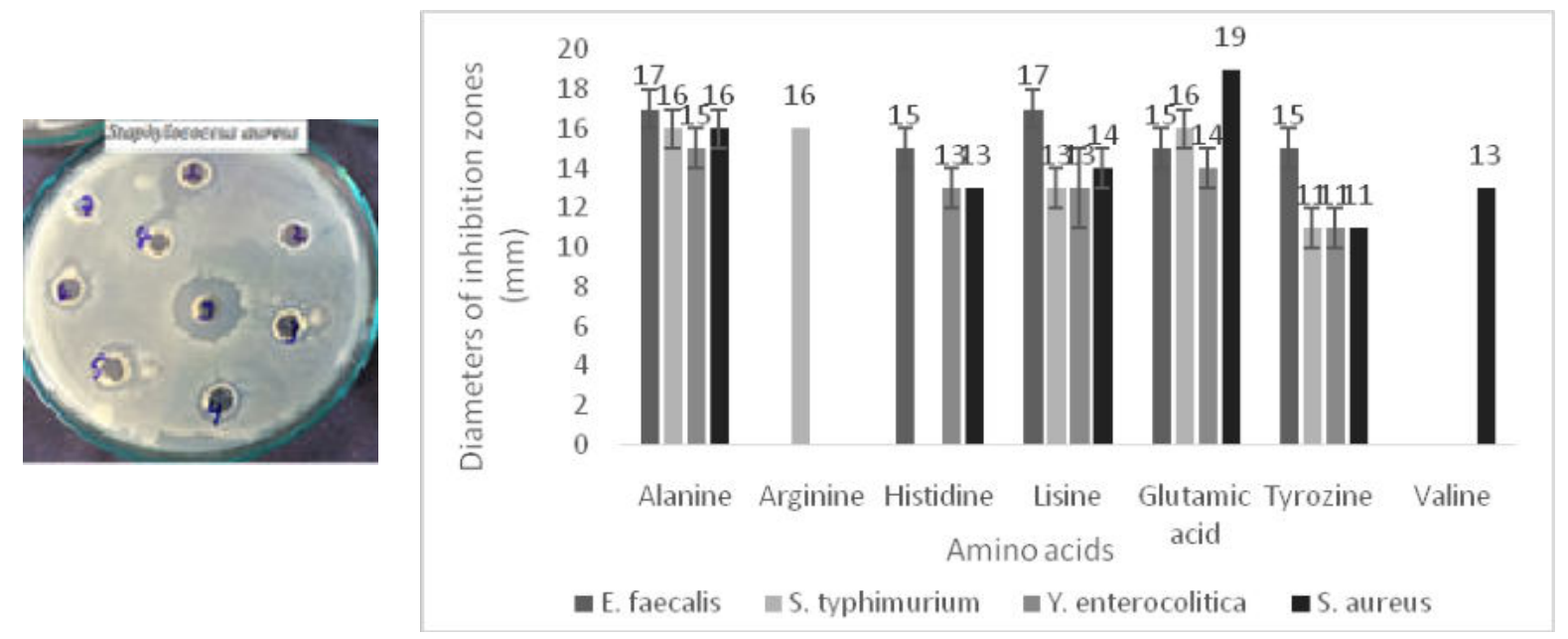

Fig. 3. Effect of different amino acid sources on the production of antibacterial substance against pathogens. 1-Alanine, 2Phenylalanine, 3-Valine, 4-Tyrosine, 5-Lysine, 6-Histidine, 7-Cystine, 8-Arginine, 9-Glutamic acid on petri dish.

ial activity was considerably decreased when metal ion sources alone were used. Maximal inhibitory zones were determined in presence of $\mathrm{MgSO} 4(15 \mathrm{~mm})$ against $E$. faecalis and combination with $\mathrm{CaCO} 3$ (19 $\mathrm{mm}$ ) was increased the antibacterial activity against all tested pathogens while $\mathrm{CaCO} 3$ alone had no effect.

The effect of different temperature and $\mathrm{pH}$ on antibacterial substance activity have been outlined in Figure 5. Treatment of antibacterial substance at 30, $37,40,50,55^{\circ} \mathrm{C}$ did not show significant from the control. The maximum antibacterial substance activity was obtained at $37^{\circ} \mathrm{C}$ as control against $Y$. enterocolitica $(17 \mathrm{~mm})$, although $40{ }^{\circ} \mathrm{C}$ was also effective at promoting antibacterial activity, as the observed inhibition zone was $15 \mathrm{~mm}$ against $S$. typhimurium.

Generally, the maximum activity was obtained at an initial $\mathrm{pH}$ of 7.0. At lower and higher $\mathrm{pH}$ values were reduced the antibacterial substance activity. The highest zone of inhibition was obtained for $Y$. enterocolitica $(17 \mathrm{~mm})$ at $\mathrm{pH} 7.0$ and the lowest $E$. faecalis and $Y$. enterocolitica $(11 \mathrm{~mm})$ at $\mathrm{pH} 4.0$, E. faecalis and $Y$. enterocolitica $(10 \mathrm{~mm})$ at $\mathrm{pH} 9.0$. No zone of inhibition was recorded below $\mathrm{pH} 4.0$ and above $\mathrm{pH}$ 9.0.

Modified medium determined for each bacterial strainswas found different. But the best results for each parameters were selected to determine modified medium. According to these results, the maximum production of antibacterial substance was obtained inoptimized medium (consisted of $1.5 \%$ glucose, $0.1 \%$ of tryptone, $0.05 \%$ of $\mathrm{MgSO} 4+\mathrm{CaCO} 3$ and $0.5 \%$ glutamic acid at $\mathrm{pH} 7.0$ ).

The production of antimicrobial substance in the modified medium showed a slight increase compared to each test bacteria according to the control medium (Table 1). An increase of $17 \%$ for S. typhimurium, 5\%

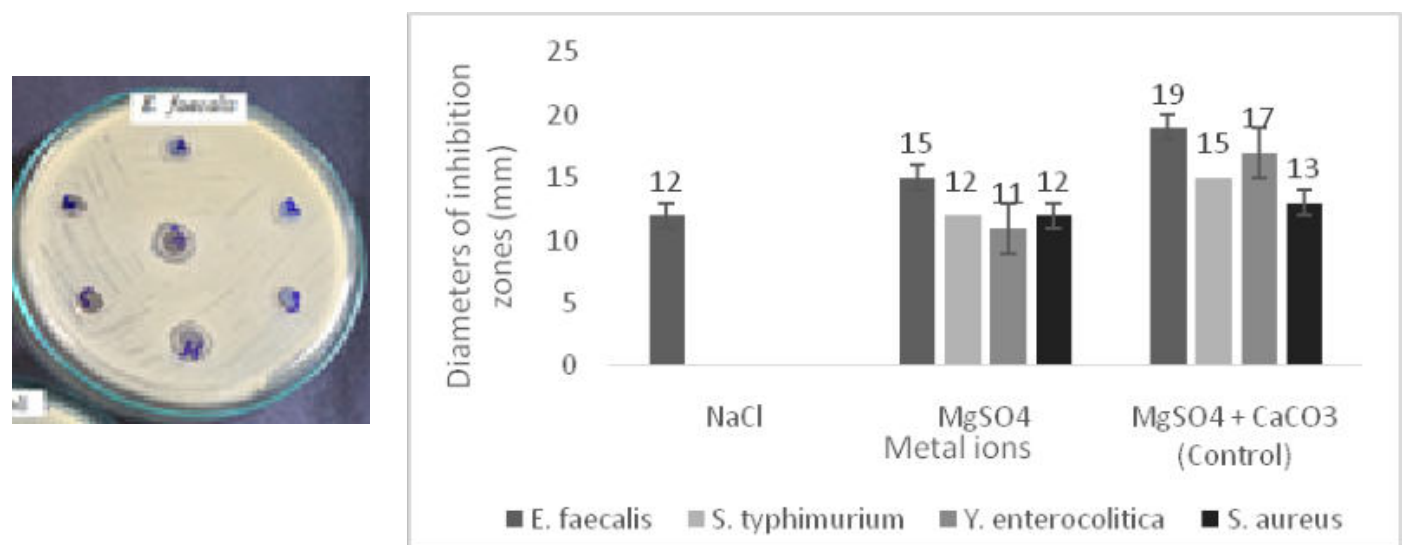

Fig. 4. Effect of different metal ions on the production of antibacterial substance against pathogens. 1-CaCl2, 2-FeSO4, 3.LiSO4, 4-NaCl, 5-KCl,6.MnSO4, 7-MgSO4 on petri dish. 


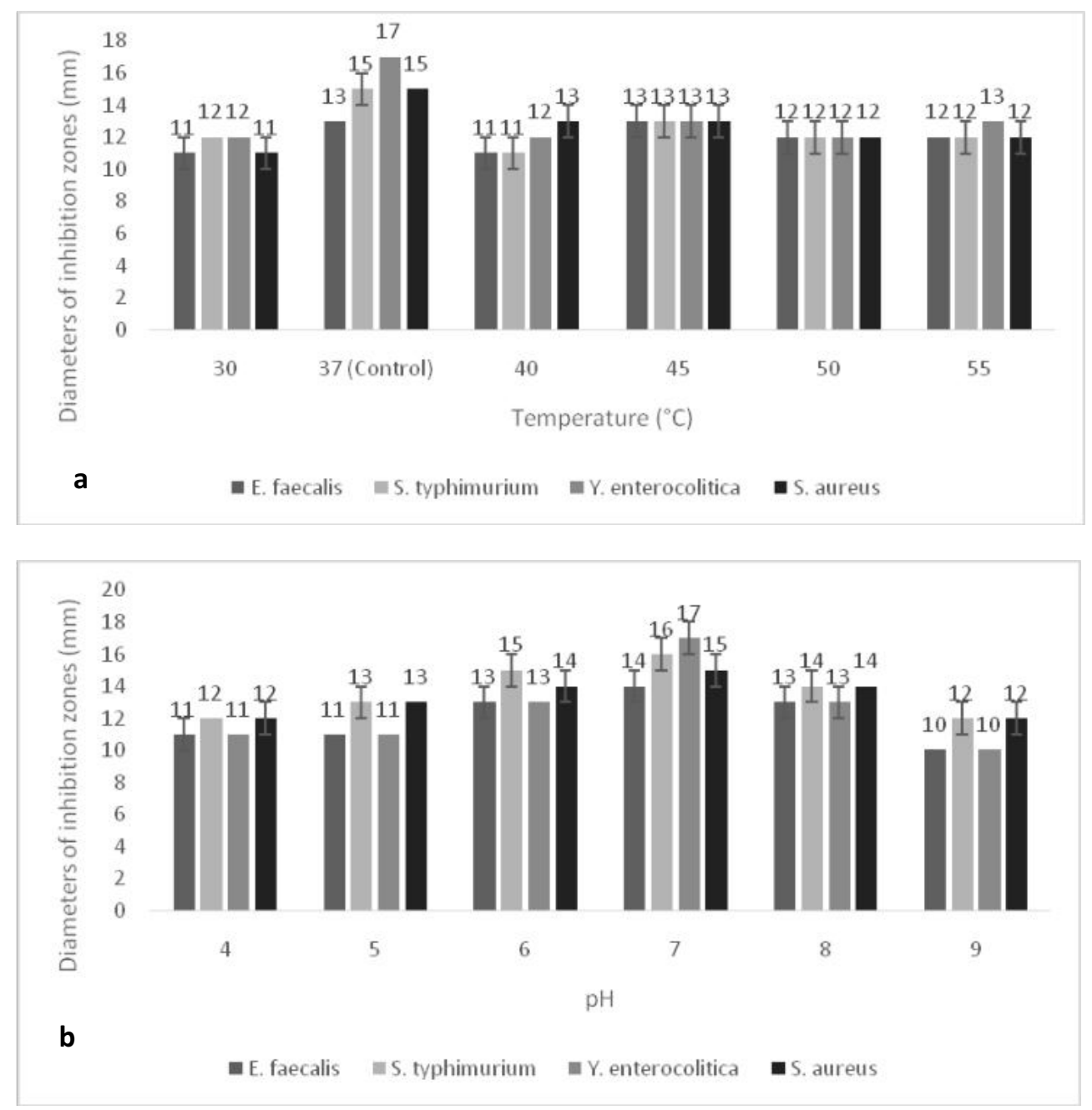

Fig. 5. Effect of temperatures (a) and pH (b) on antibacterial substance activity against pathogens.

for $Y$. enterocolitica, $6 \%$ for $S$. aureus, and $7 \%$ for $E$. faecalis was found.

\section{DISCUSSION}

Prior knowledge and experience in developing a suitable basal medium play a significant role in the further media optimization [17]. The optimization of various physical and nutritional growth parameters caused an increase in the antibacterial substance activity; the important physical factors that determine the bioprocess are temperature, $\mathrm{pH}$, agitation, inoculum size and inoculum age [18]. In a previous study,

Table 1. Comparison of antibacterial substance acitivity in modified and basal medium against bacteria tested

\begin{tabular}{lcc}
\hline Bacterial Strains & $\begin{array}{c}\text { Inhibition zones in } \\
\text { control medium } \mathbf{( m m})\end{array}$ & $\begin{array}{c}\text { Inhibition zones in modified } \\
\text { medium } \mathbf{( m m})\end{array}$ \\
\hline Salmonella typhimurium & $17 \pm 2$ & $20 \pm 1$ \\
Yersinia enterocolitica & $17 \pm 1$ & $18 \pm 2$ \\
Staphylococcus aureus & $15 \pm 2$ & $16 \pm 1$ \\
Enterococcus faecalis & $13 \pm 1$ & $14 \pm 2$ \\
\hline
\end{tabular}

Data are given as mean \pm standard deviation 
it was observed that the antibacterial substance showed inhibitory activity against the test pathogens (Gram-negative Y. enterocolitica (ATCC 9610) and S. typhimurium (ATCC 14028) the Gram-positive bacteria, S. aureus (ATCC 25923) and E. faecalis (ATCC 29212). Maximum zone of inhibition was observed against $S$. aureus $(19 \mathrm{~mm})$ followed by $Y$. enterocolitica $(17 \mathrm{~mm})$ [14]. Therefore, in this study, the effects of nutritional and physical parameters were investigated for the production of antibacterial substance from B. laterosporus EA62.

Different carbon sources, such as maltose [19], dextrose [20], arabinose [21], fructose [22], and mannitol [23] have been reported to be suitable for the activity of antibiotic substances in different microorganisms. In this study, among the different carbon sources studied, addition of glucose to the basal medium showed highest antibacterial activity against all bacteria tested. In addition, the antagonistic activity of bacteriocinas an antimicrobial substance was also increased when glucose was added to the medium in a previous studies $[24,25]$. Some studies have reported that organic or inorganic nitrogen sources influence enzyme activity. It was previously reported that antimicrobial activity was considerably decreased when nitrogen sources alone were used in the fermentation media [22]. In present study, higher antibacterial substance activity was achieved when tryptone and yeast extract against all bacteria tested used as a nitrogen source. Similar results were observed for antibiotic activity in batch cultures of Bacillus laterosporus ST-1 when grown in the presence of yeast extract in glucose broth [26]. In addition, inhibitory effect of antibacterial substance was only observed for MgSO4 and $\mathrm{MgSO} 4+\mathrm{CaCO} 3$ combination among the metal ions, no antibacterial activity was obtained in the presence of the others. The addition of MgSO4increased iturin A activity by Bacillus amyloliquefaciens B128 $[27,28]$, indicating that that rare earth metals and trace metals, notably manganese, zinc and iron, may trigger the activity of various secondary metabolic pathways. The use of amino acids as nitrogen sources can inhibit the synthesis of secondary metabolites [29]. Therefore, some amino acids were tested in the basal medium to determined inhibitory effects of the antibacterial substance in this study and glutamic acid has found as the most effective amino acid on antibacterial substance activity against all bacteria tested while phenylalanine and cysteine showed no inhibitory effects on antibacterial substance production.

The effect of different temperature and $\mathrm{pH}$ on antibacterial substance activity was also determined and maximum antibacterial substance activity was found at $37^{\circ} \mathrm{C}$ and $\mathrm{pH} 7.0$ against all bacteria tested. A similar result for temperature was previously reported, but the antibiotic showed maximum activity at $\mathrm{pH} 8.0$ [30]. Although the maximum antibiotic activity occurred at a low temperature $\left(30^{\circ} \mathrm{C}\right)$ and at $\mathrm{pH} 7.0$ [26], antibiotic activity was achieved at temperatures as high as $40{ }^{\circ} \mathrm{C}$ and at $\mathrm{pH} 7.0$ [31].

\section{CONCLUSION}

In summary, this is a novel antibacterial substance from the soil microorganism, Brevibacillus laterosporus EA62, and it is active against some important gram negative and positive pathogens. The effects of nutritional and physical parameters on antibacterial substance activity were examined. The amtibacterial substance produced by EA62 may be potential applications for the pharmaceutical industry and could be a promising candidate for infection diseases after purified and characterized in the near future.

\section{Authors' Contribution}

Study Conception: ED, AA, AUA; Study Design: ED, AA, AUA; Supervision: ED; Funding: ED; Materials: ED, AUA; Data Collection and/or Processing: ED, AA, AUA; Statistical Analysis and/or Data Interpretation: ED, AA, AUA; Literature Review: ED, AA; Manuscript Preparation: ED, AA and Critical Review: ED.

\section{Conflict of interest}

The authors disclosed no conflict of interest during the preparation or publication of this manuscript.

\section{Financing}

The authors disclosed that they did not receive any grant during conduction or writing of this study.

\section{REFERENCES}

1. Dancer SJ. How antibiotics can make us sick: The less obvious 
adverse effects of antimicrobial chemotherapy. Lancet Infect Dis 2004;4:611-9.

2. Courtis S, Cappellano C, Ball M, Francois F, Helynck F, Martizez A, et al. Recombinant environmental libraries provide access to microbial diversity for drug discovery from natural products. Appl Environ Microbiol 2003;69:49-55.

3. Viscardi M, Perugini AG, Auriemma C, Capuano F, Morabito $\mathrm{S}$, Kim KP, et al. Isolation and characterisation of two novel coliphages with high potential to control antibiotic-resistant pathogenic Escherichia coli (EHEC and EPEC). Int JAntimicrob Agents 2008;31:152-7.

4. Wang J, Haddad NI, Yang SZ, Mu BZ. Structural characterization of lipopeptides from Brevibacillus brevis HOB1. Appl Biochem Biotechnol 2010;160:812-21.

5. Mogi T, Kita K. Gramicidin S and polymyxins: the revival of cationic cyclic peptide antibiotics. Cell Mol Life Sci 2009;66:3821-6.

6. Smirnova TA, Minenkova IB, Orlova MV, Lecadet MM, Azizbekyan RR. The crystal-forming strains of Bacillus laterosporus. Res Microbiol 1996;147:343-50.

7. Huang X, Tian B, Niu Q, Yang J, Zhang L, Zhang K. An extracellular protease from Brevibacillus laterosporus G4 without parasporal crystals can serve as a pathogenic factor in infection of nematodes. Res Microbiol 2005;156:719-27.

8. Desjardine K, Pereira A, Wright H, Matainaho T, Kelly M, Andersen RJ. Tauramamide, a lipopeptide antibiotic produced in culture by Brevibacillus laterosporus isolated from a marine habitat: structure elucidation and synthesis. J Nat Prod 2007;70:1850-3. 9. Krachkovskii SA, Sobol AG, Ovchinnikova TV, Tagaev AA, Yakimenko ZA, et al. Isolation, biological properties, and spatial structure of antibiotic loloatin A. Russ J Bioorg Chem 2002;28:269-73.

10. Usta Ak A, Demirkan E. The effect of growth parameters on the antibiotic activity and sporulation in Bacillus spp. isolated from soil. J Microbiol Biotech Food Sci 2013;2:2310-3.

11. Parente E, Ricciardi A, Addario G. Influence of $\mathrm{pH}$ on growth and bacteriocin production by Lactococcuslactis subsp. lactis 140NWC during batch fermentation. Appl Microbiol Biotechnol 1994;41:388-94.

[12] Moortvedt-Abildgaard CI, Nissen-Meyer J, Jelle B, Grenov $\mathrm{B}$, Skaugen M, Nes IF. Production and $\mathrm{pH}$-dependent bactericidal activity of lactocin S, a lantibiotic from Lactobacillus sake L45. Appl Environ Microbiol 1995;61:175-9.

13. Jose PA, Sivakala KK, Jebakumar SRD. Formulation and statistical optimization of culture medium for improved activity of antimicrobial compound by Streptomyces sp. JAJ06. Int J Microb 2013;1-9.

14. Usta Ak A, Demirkan E, Cengiz M, Sevgi T, Zeren B, Abdou M. Optimization of culture medium for the production and partial purification and characterization of an antibacterial activity from Brevibacillus laterosporus Strain EA62. Rom Biotechnol Lett 2019;24:705-13.

15. Wang H, Lu Y, Zhang X, Hu Y, Yu H, Liu J, et al. The novel antimicrobial peptides from skin of Chinese broad-folded frog, Hylaranalatouchii (Anura:Ranidae). Peptides 2009;30:273-82.
16. Kavanagh F. Analytical Microbiology. Vol. 2. New York: Ahead Press, 1972.

17. Jia B, Jin ZH, Mei LH. Medium optimization based on statistical methodologies for pristinamycins production by Streptomyces pristinaespiralis. Appl Biochem Biotechnol 2008; 144:133-43.

18. Ashokkumar B, Kayalvizhi N, Gunasekaran P. Optimization of media for $\beta$ fructofuranosidase production by Aspergillus nigerin submerged and solid state fermentation. Process Biochem 2001;37:331-8.

19. Singha P,Roymon MG. Antibiotic potential of soil actinomycetes under influence of physical and nutritioial parameters. Indian J Sci Res 2017;13:203-7.

20. Linda H, Al-Ghazali R. Omran. Optimization of medium composition for antibacterial metabolite activity from Streptomyces sp.Asian J Pharm Clin Res 2017;10:381-5.

21. Kadiri SK, Yarla NS. Optimization of antimicrobial metabolites activity by Streptomyces fradiae. Int $\mathrm{J}$ Pharm Sci 2016; 7:223-5.

22. Kumar SN, Siji JV, Ramya R, Nambisan B, Mohandas C. Improvement of antimicrobial activity of compounds produced by Bacillus sp. associated with a Rhabditid sp. (entomopathogenic nematode) by changing carbon and nitrogen sources in fermentation media. J Microbiol Biotech Food Sci 2012;1:1424-38.

23. Abdelghani T. Activity of antibacterial and antifungal metabolites by (S.albovinaceus) strain no.10/2 and media optimization.AmInt J Bio 2017;5:1-24.

24. Ekhay O, Ouhsassi M, Abdeltif EH, Idaomar M, Abrini J. Optimization of bacteriocin-like production by Enterococcus durans E204 isolated from camel milk of Morocco. Curr Res Microbiol Biotechnol 2013;1:155-9.

25. Todorov SD. Bacteriocin production by Lactobacillus plantarum AMA-K isolated from Amasi, a zimbabwean fermented milk product and study of the adsorption of bacteriocin AMA-K to Listeria sp. Braz J Microbiol 2008;39:178-87.

26. Kalpana S, Bagudo AI, Aliero AA. Effect of inhibitory spectrum and physical conditions on the activity of antibiotic substance from B. laterosporus ST-1. Niger J Microbiol 2010;24:2134-9.

27. Lin HY, Rao YK, Wu WS, Tzeng YM. Ferrous ion enhanced lipopeptide antibiotic iturin A activity from Bacillus amyloliquefaciens B128. Int J Appl Sci Eng 2007;5:123-32.

28. Ochi K, Hosaka T. New strategies for drug discovery: activation of silent or weakly expressed microbial gene clusters. Appl Microbiol Biotechnol 2013;97:87-98.

29. Martin JF, Demain AL. Fungal development and metabolite formation. In: The Filamentous Fungi. Eds. Smith JE, Berry DR, Arnold, London. 1978;3:426-50.

30. Bisht SS, Praveen B, Panda A, Rajakumar V. Isolation, purification and characterization of bacitracin from Bacillus sp. Int J Pharm Sci 2011;3:136-8.

31. Joshi RD, Hamde VS, Umrikar AM, Kulkarni SS, Bhate MA. Studies on activity of peptide antibiotic by thermotolerant Bacillus sp. Int Multidis Res J 2012;2:30-3. 